Memorias de militancia en Tucumán: los cuentos de los viejos guerreros

Rossana Nofal

Anuario № 26 / ISSN 1853-8835 / pp. 72-89 /2014

http://anuariodehistoria.unr.edu.ar/ojs/index.php/Anuario/index

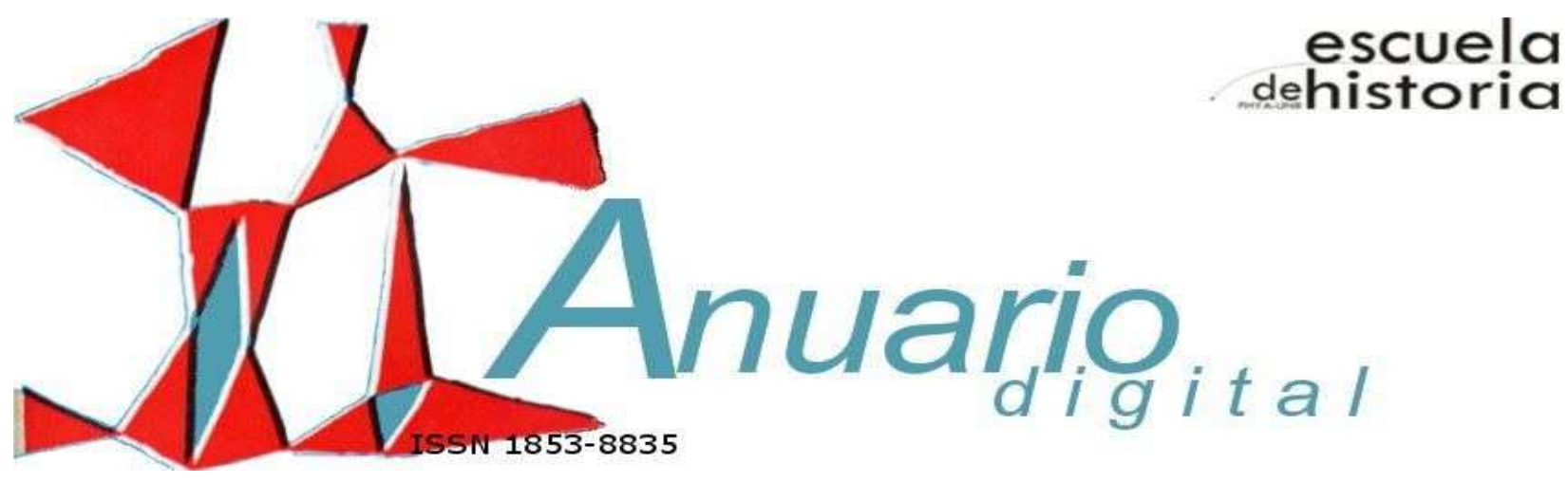

Memorias de militancia en Tucumán: los cuentos de los viejos guerreros

Memories of militancy in Tucumán: old warriors tales

ROSSANA NOFAL

(Instituto de Investigaciones sobre el Lenguaje y la Cultura

Universidad Nacional de Tucumán

Consejo Nacional de Investigaciones Científicas y Técnicas; Argentina)

rossananofal@yahoo.com.ar

RESUMEN

La serie narrativa de la memoria de la dictadura en Tucumán es disímil. Se construye entre los límites del género testimonial y del relato periodístico con el contrapunto de las voces de los autores que la piensan desde Buenos Aires y los que la piensan desde Tucumán. Hay un cruce de temporalidades pero también de espacios geográficos y de circuitos de lectura. Este trabajo propone la lectura contrapuesta de las "memorias contra memorias" en términos de Jelin (2006). Tucumán se representa como un campo de batalla en los testimonios de la política de los años '70. Señalo por su importancia dos libros publicados inicialmente en el exterior: Soldados de Perón. Los Montoneros de Richard Gillespie (1982) y Dossier secreto. El mito de la "guerra sucia" en Argentina, de Martin Edwin Andersen (1993). En el año 2005, Eduardo Anguita publica en Buenos Aires su novela testimonial, La Compañía de Monte y Lucía Mercado publica en el mismo año en Tucumán, Santa Lucía de Tucumán, La Base, libro con sello editor de la autora. Desde la escritura literaria y con una fuerte apuesta a la construcción metafórica sobre la dictadura en Tucumán, se inscribe la novela de

Esta obra está sujeta a la Licencia Reconocimiento-NoComercial-Compartirlgual 4.0 Internacional de Creative Commons. http://creativecommons.org/licenses/by-nc-sa/4.0/ 


\section{Memorias de militancia en Tucumán: los cuentos de los viejos guerreros}

Horacio Elsinger, La virgen de los ojos cerrados, publicada recientemente en Buenos Aires. En los libros del corpus, el pasado violento de la provincia aparece inscripto con sus múltiples complejidades y organizado por marcadas antinomias y la gran división del "aquí" y el "allá". La metáfora de Elsinger no engendra un nuevo orden testimonial sino que explicita los silencios.

Palabras clave: Guerra; militancia; memorias; metáfora

ABSTRACT

The narrative series that collects the memory of the dictatorship in Tucuman is dissimilar. It is constructed within the boundaries of both, the testimonial genre and the journalistic narrative, along with the counterpoint formed by the voices of those writing from Buenos Aires and those writing locally in Tucumán. Temporalities juxtapose with geographical spaces and reading circuits. The present work offers the opposing readings of "memories against memories", as defined by Jelin (2006). Tucumán is portrayed as a battlefield in the testimonies of 1970's politics. Because of their significance, I mention two books originally published abroad: Richard Gillespie's Soldiers of Peron. Argentina's Montoneros, and Martin Edwin Andersen's Dossier Secreto: Argentina's Desaparecidos and the Myth of the Dirty War (1993). In 2005, Eduardo Anguita publishes his testimonial novel La compañía de Monte (The Monte company), in Buenos Aires, while Lucía Mercado publishes in Tucumán Santa Lucía de Tucumán. La Base (Santa Lucía of Tucuman. The Base), during the same year. Horacio Elsinger's novel La virgen de los ojos cerrados (The virgin with closed eyes), recently published in Buenos Aires, is inscribed within the sphere of literary writing, placing a heavy bet on the metaphoric construction about the dictatorship in Tucuman. In the literature corpus, the town's violent past is recorded with its multiple complexities, and organised by marked antinomies and the great "here/there" division. Elsinger's metaphor does not create a new testimonial order; instead, it makes silences explicit.

Keywords: war; militancy; memories; metaphor

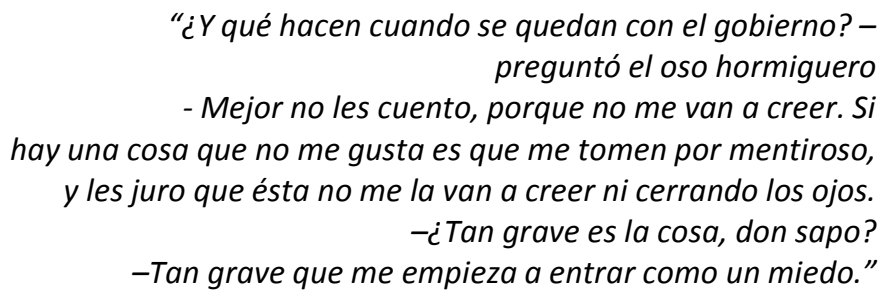

Gustavo Roldán, Sapo en Buenos Aires

73

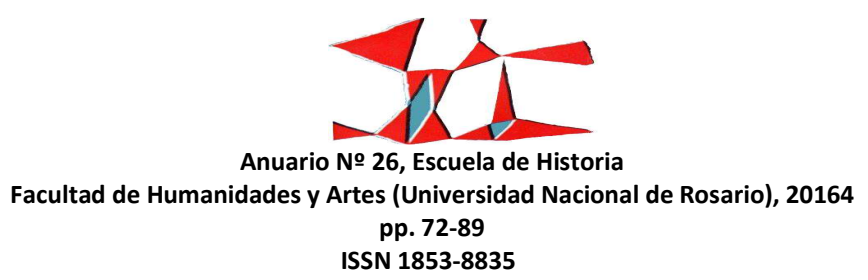


La experiencia que se trasmite de boca en boca, dice Walter Benjamin, es la de los narradores. Cuando alguien realiza un viaje, puede contar algo. El narrador, se presenta entonces, al igual que en el relato de Gustavo Roldán, como alguien que viene de muy lejos. ¿Quién nos va a contar el cuento de la dictadura: el testimonio o la literatura, los historiadores, los escritores de Buenos Aires o todos juntos y mezclados? "Lo que más me gusta es volar", dice el sapo de Gustavo Roldán y empieza a contar las ideas "foráneas" que trae al monte chaqueño cada vez que viaja a Buenos Aires. Del tema de los militares, como de los dragones ingleses, siempre prefiere conversar a solas. Se hace necesario, señala Susana Kaufman ${ }^{1}$, revisar los silenciamientos en los relatos memoriosos para comprender si llevan a la idealización del imaginario emancipatorio de los setenta, si entran en pactos de silencio para omitir zonas de dolor o si evitan la confrontación con los valores, los sentidos ideológicos y los modos de la política de aquellos años.

Desde su punto inicial, la escritura testimonial disputa un territorio en la categoría artística, en el espacio mismo de la literatura. En este sentido el testimonio actúa por delegación, se ocupa de las cosas que se hablan en los costados de las grandes historias. De las cosas que están al otro lado del río, del país, del puente, de las columnas, de las paredes, de las ventanas clausuradas, de las tapias fuera de lugar. Todo se sucede en la misma mesa de trabajo, como en el libro de Laura Alcoba, entre las armas y el dulce de leche².

\section{Tucumán: los cuentos}

La serie narrativa de la memoria de la dictadura en Tucumán es disímil. Se construye en los límites del género testimonial y del relato periodístico y el contrapunto de las voces de los autores que la piensan desde Buenos Aires y los que la piensan desde Tucumán. Hay un cruce de temporalidades pero también de espacios geográficos y de circuitos de lectura.

Tucumán es punto de referencia en la constitución de un imaginario revolucionario. Una geografía que actúa como centro de la cultura, de la militancia política y de la represión. En este sentido es importante revisar la cuestión de las temporalidades diferentes al momento de pensar en los relatos de militancias.

\footnotetext{
1 Jelin, Elizabeth y Kaufman, Susana (comps.); Subjetividad y figuras de la memoria; Siglo XXI; Buenos Aires; 2006 ; p. 68.

2 "Por el camino de vuelta, me detengo al borde de una u otra zanja de aguas servidas. Tengo un pequeño frasquito para encerrar renacuajos. Por fin vuelvo rápido a tomar la merienda. Hoy es el día en que se limpian las armas. Yo trato de encontrar un pequeño sitio limpio en la mesa atestada de hisopos y cepillos empapados en aceite. No quiero ensuciar mi rodaja de pan untada con dulce de leche." Alcoba, Laura; La casa de los conejos; Edhasa; Buenos Aires; 2007; p. 84.
}

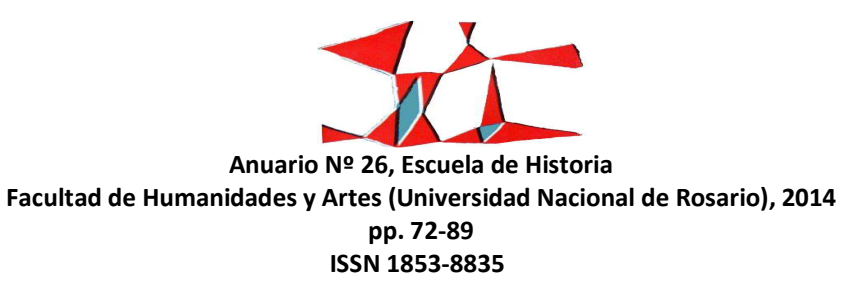




\section{Memorias de militancia en Tucumán: los cuentos de los viejos guerreros}

Tucumán se representa como un campo de batalla en los testimonios de la política de los años '70. Señalo por su importancia dos libros publicados inicialmente en el exterior: Soldados de Perón. Los Montoneros de Richard Gillespie ${ }^{3}$ y Dossier secreto. El mito de la "guerra sucia" en Argentina, de Martin Edwin Andersen". En

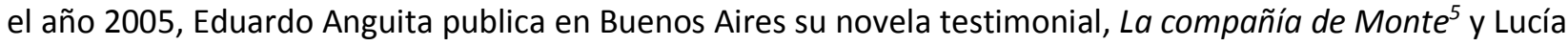
Mercado publica en el mismo año en Tucumán, Santa Lucía de Tucumán, La Base ${ }^{6}$, libro con sello editor de la autora. En todos los libros, el pasado violento de la provincia aparece inscripto con sus múltiples complejidades y organizado por marcadas antinomias y la gran división del "aquí" y el "allá". Martin Andersen, Eduardo Anguita y Lucía Mercado coinciden en identificar un discurso sobre la guerra en la provincia, aunque con modulaciones muy distintas. Andersen apela a la evidencia documental; Mercado inscribe largas entrevistas realizadas en el pueblo de Santa Lucía y Anguita le apuesta a la construcción de una novela con la centralidad de una historia de amor. El cuento sobre la extrañeza más absoluta es quizás, el que se cuenta desde Tucumán. Lucía Mercado reitera una y otra vez la palabra escuchada en sus entrevistas: los problemas venían de otro lado; los traían, por igual los extremistas y los militares; todos eran "rubios". 7

Empezamos a ver gente rara en nuestras colonias, en el pueblo. Santa Lucía es pueblo chico, al de afuera se lo conoce en el momento. Eran gente de otro lado, muchachos muy lindos, chicas bien vestidas. Rubitos, con barba, porteños que andaban pelando cañas con los peones de nosotros. Y se iban a los surcos, al "cerco", a los cañaverales y se juntaban con la gente pobrecita, les llevaban comida, les hablaban de darles cosas, mercadería y zapatillas. ¡Qué le van a hablar de revolución a esa gente! ¡Eran analfabetos y muy pobres! Nunca habían salido de aquí. Y empiezan a hacer paro por cualquier cosa. (...) Pasaba que si era para boconear yo me ponía adelante y de frente, pero en eso de andar a las escondidas y con armas, no. Yo no les servía para el asunto de la guerrilla. ${ }^{8}$

\footnotetext{
${ }^{3}$ Gillespie, Richard; Soldados de Perón. Los Montoneros; Grijalbo; Buenos Aires; 1986.

${ }^{4}$ Andersen, Martin Edwin; Dossier secreto. El mito de la "guerra sucia" en Argentina; Sudamericana; Buenos Aires; 2000.

${ }^{5}$ Anguita, Eduardo; La compañía de monte; Planeta; Buenos Aires; 2005.

${ }^{6}$ Mercado, Lucía; Santa Lucía de Tucumán. La Base; Ediciones del Autor; Buenos Aires; 2005.

${ }^{7}$ Es interesante pensar en la ficción de memoria de la película Los rubios de Albertina Carri, uno de los cuentos más importantes del género testimonial.

${ }^{8}$ Mercado, Lucía; Op. Cit; p. 77.
}

75

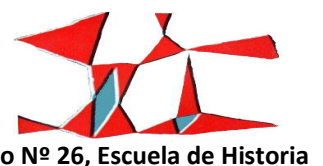

Facultad de Humanidades y Artes (Universidad Nacional de Rosario), 20164

pp. 72-89

ISSN 1853-8835 
Ángel Rama ${ }^{9}$ propone la categoría de "espesor" para explicar la superposición, en un mismo tiempo y lugar, de diferentes expresiones literarias con dos comportamientos extremos. Me interesa repensar esta categoría para dar cuenta de los diferentes registros de memorias ubicados en geografías diferentes. En términos de Rama, las diferentes modulaciones pueden guardar escasa vinculación y desplegarse paralelamente o ser capaces de enfrentamientos que se traducen en polémicas. Igual situación se plantea si pensamos la configuración de los relatos de acuerdo a las posiciones de los autores en relación al centro casi hegemónico de las representaciones de las memorias nacionales.

En los términos de las continuidades y de las rupturas tendríamos que pensar otra vez estos modelos binarios que indudablemente nos atraviesan y organizan nuestros cruces: el interior, el sur, el norte. Los del lado de acá, los del lado de allá, los del otro lado del río. Para que los productos puedan circular entre todos los sistemas literarios necesitan de un lector capaz de iluminar las contradicciones de un discurso que se presupone uniforme y fundado en una idea de centralidad.

Hay infinidad de huellas diseminadas en los lugares, en los pueblos, en los relatos. Las múltiples verdades están inscriptas en el ejercicio de "contar el cuento" porque, como dice Josefina Ludmer ${ }^{10}$, ese contar funda el ejercicio de la diferencia y construye una escucha que puede pensar las modulaciones de la crítica a las armas "enloquecedoras" en términos de un presente memorioso. La desconexión entre dos producciones coetáneas de literatura revela que se encuentra en los puntos más alejados del sistema. Así, Tucumán se dice antes desde Buenos Aires y sus representaciones se constituyen en instancias fijas dentro del sistema literario.

Matías desplegó un mapa grande del Norte argentino, de ésos con verdes en las selvas tropicales y marrones en las montañas. Parecía fascinado, como un escolar que estudia geografía. -Así vamos a ir liberando zonas dijo, mientras su índice caminaba hacia un corredor que unía Tucumán, Salta, Jujuy, Bolivia y Perú. Concentró la atención de todos y empezó a contar el plan estratégico del comandante Santucho: con la primera zona bajo el control de la guerrilla, pedirían un gobierno autónomo a las Naciones Unidas. ${ }^{11}$

\footnotetext{
${ }_{9}^{9}$ Rama, Ángel; La ciudad letrada; Fundación Ángel Rama; Montevideo; 1985.

${ }^{10}$ Ludmer, Josefina; Los procesos de construcción del relato; Sudamericana; Buenos Aires; 1977.

${ }^{11}$ Anguita, Eduardo; La compañía de monte; Planeta; Buenos Aires; 2005; p. 116.
}

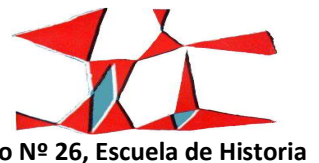




\section{Memorias de militancia en Tucumán: los cuentos de los viejos guerreros}

En la novela de Anguita, los guerrilleros son buenos y bellos. Los dos relatos replican la idea de una literatura de virtudes propuesta por Hebert Gatto; una literatura de clausura que supone la negación de elementos ambiguos o la construcción de un doble crítico que destrone a su contraparte. Hablamos de "una narrativa sustentada en la preponderancia de los méritos individuales de los guerrilleros -sus virtudes éticas y a veces estéticas- inhibe los análisis sobre el movimiento como organización supraindividual dotada de características propias." ${ }^{12}$ Los guerrilleros son extraños y lejanos; tienen una peligrosa similitud física con los militares, son más altos, vienen de afuera, "no son de acá". Indudablemente se imponen los valores de lo "familiar" y la amenaza es sofocada; se vuelve necesario controlar su novedad y la sugestividad de sus acciones.

La voluntad de trabajar sobre la memoria de la violencia política de los '70 en el espesor del sistema literario argentino no es una inquietud aislada de un contexto político y cultural específico. Aunque la investigación persigue reflexiones de carácter general, se piensa desde un lugar particular: Tucumán, en tanto provincia en "ruinas". Si bien han cambiado las preguntas y los personajes que construyen los testimonios, el saber sigue fuertemente ligado a un poder que lo autoriza. No puede desvincularse de los protocolos iniciales y de una expresividad potenciada por la cercanía de los lazos familiares. Creo que la peligrosidad de la palabra guerra interpela fuertemente los presupuestos del género y funda un espacio en el que la "antinaturaleza" es la ley.

Elizabeth Jelin ${ }^{13}$ señala que las narrativas de las memorias tienen una temporalidad propia que no puede homologarse a la linealidad del paso del tiempo. A esta no linealidad, Jelin la entiende a partir de la existencia de los "emprendedores de memorias" que no dejan que ese pasado se olvide, pero también por la presencia de las nuevas generaciones y sus preguntas en relación al pasado. La especificidad de un discurso abierto por sus extremos que no se clausura, se complejiza constantemente. Las figuras de conflicto y disputa permiten pensar las memorias no sólo como un tema sino como una metodología para releer el campo de la escritura testimonial y la poética de sus héroes convertidos en personajes de los relatos sobre los hechos. ${ }^{14}$

\footnotetext{
${ }^{12}$ Gatto, Herbet; El cielo por asalto. El Movimiento de Liberación Nacional (Tupamaros) y la izquierda uruguaya (1963-1972); Taurus; Montevideo; 2004; p. 379.

${ }_{13}$ Jelin, Elizabeth; Los trabajos de la memoria; Siglo XXI; Buenos Aires; 2002.

${ }^{14}$ Nofal, Rossana; "Desaparecidos, militantes y soldados"; en Crenzel, Emilio (comp.); Los desaparecidos en Argentina; Biblos; Buenos Aires; 2010; p. 53.
}

77

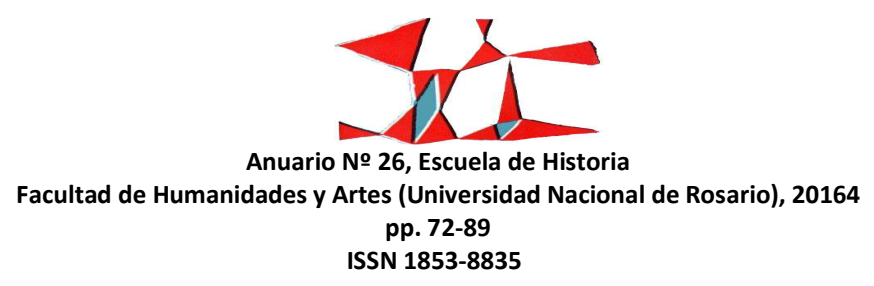


La propuesta es la de realizar un ejercicio que restituya las huellas de un pasado que "ha sido" pero se encuentra ausente. Coincido con Héctor Schmucler para quien la violencia de los '70 "configuró un tipo singular de guerra. Negarla u otorgarle calificativos amparadores de los crímenes (guerra sucia, por ejemplo) sólo confunde. Desdibuja pero no borra". ${ }^{15}$ Hay dos discusiones comprometidas en este punto. Por un lado, el campo semántico de la pregunta ¿cómo se dice Tucumán? con sus respuestas y sus inferencias. Por otro lado, ¿̇cómo se dice guerra cuando se habla de Tucumán?

La centralidad de Buenos Aires a menudo lleva a una identificación del país en su totalidad con una ciudad. Esta situación se inscribe en una tradición que plantea a la ESMA como emblema de toda la represión, en todo el país, a todos los signos políticos del conflicto de los años setenta. Para dar sólo un ejemplo, las exhumaciones y reconocimientos de cuerpos encontrados en el Pozo de Vargas, tema que ha conmovido a la ciudad no han tenido la repercusión nacional (o "porteña") de otros hallazgos. Sabemos que hay enormes brechas entre las memorias hegemónicas o centrales y las memorias locales. De ahí la intención de inventariar las escrituras testimoniales producidas sobre la provincia de Tucumán, tanto las escrituras que se producen en nuestro territorio como las escrituras que sobre Tucumán se producen en Buenos Aires y tienen una circulación más amplia. Por lo tanto, no es posible imaginar procesos de uniformización de memoria o de unificación de "las" memorias en "una" sola y verdadera, sino escenarios con diversos actores que pugnan porque sus particulares sentidos y subjetividades sean reconocidos.

En el Tucumán de La compañía de Monte de Anguita, se reiteran escenas ritualizadas de un relato del sufrimiento, emparentados con una literatura de las virtudes, con una fuerte gravitación de la antinomia héroe y traidor. El núcleo más complejo de esta literatura es la concreción de las entrevistas a los ex militantes comprometidos con la lucha armada en nuestra provincia.

El lector extraño es quien abre otra puerta de entrada, más plural, en el espesor de la literatura testimonial. Es precisamente él quien puede imaginar una síntesis de lo heterogéneo y dar cuenta de las distintas mediaciones del relato. Corta el circuito de lo familiar en tanto sujeto ajeno al régimen de la representación testimonial. Su lugar es políticamente menos tranquilizador y puede sostener posiciones contrarias a los presupuestos del lugar de autor.

${ }^{15}$ Schmucler, Héctor (comp.); Miedos y memorias en las sociedades contemporáneas; Comunic-arte; Córdoba; 2006; p. 292.

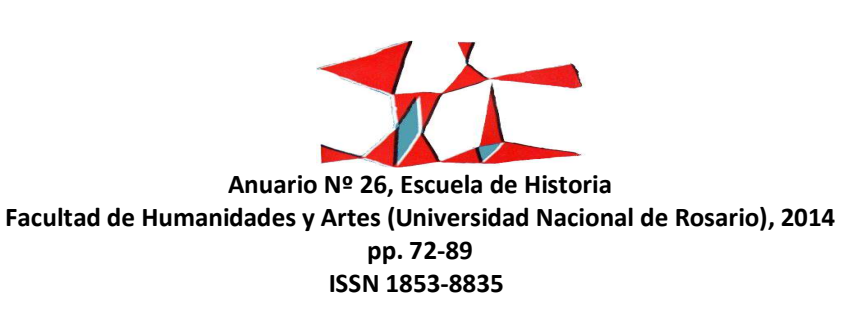




\section{Memorias de militancia en Tucumán: los cuentos de los viejos guerreros}

En el campo de producción de la escritura testimonial, las primeras palabras extranjeras que nombraron la "guerra" en Tucumán fueron Richard Gillespie, Soldados de Perón. Los montoneros (1982) y Martin Edwin Andersen, Dossier secreto. El mito de la "guerra sucia" en la Argentina (1983). Ambos textos instauran el conflictivo concepto de guerra en un campo pautado por la lógica del familismo. Desde una posición extranjera, instauran la idea de una investigación periodística hecha desde otro país. ${ }^{16}$ Gillespie construye un relato heroico sobre las organizaciones armadas ERP y Montoneros y explica la lógica de las armas. En ese mapa pautado por las imágenes de la revolución inminente y la narración de la urgencia, Tucumán ocupa un lugar estratégico.

Durante 1974 el ERP empezó a volver su atención hacia la guerrilla rural en la provincia norteña de Tucumán, esperando que el lugar se convirtiera en la "Cuba de la Argentina". ${ }^{17}$ En las nuevas circunstancias, los Montoneros carecían de capacidad para combatir directamente con las Fuerzas Amadas. Su "guerrilla de jungla”, después de una aparición en Tucumán sólo notable por su brevedad y falta de resultados, fue disuelta hacia finales de $1976 .^{18}$

Los matices de la victoria y de la derrota se entremezclan al momento de explicar las razones del fracaso. ${ }^{19}$ Gillespie inaugura una tradición romántica para explicar el pasado en clave de una modulación de la literatura de bandidos. ${ }^{20}$ "En cuanto a la respuesta favorable del público, las actividades guerrilleras de más éxito fueron, con mucho, las de estilo Robin Hood, pero éstas perdieron frecuencia al intensificarse los conflictos políticos". ${ }^{21}$ La semántica del texto expone la afinidad personal del autor más allá de las referencias materiales de los hechos. La clase de mundo a la que se abre el texto está expuesto en el uso de las

\footnotetext{
${ }^{16}$ Richard Gillespie (Wigan, Lancashire, 1952) reside en Argentina entre 1975 y 1976 mientras reúne material sobre la izquierda peronista con vistas a su doctorado, defendido en 1979. El libro con título original Soldiers of Perón, Argentina's Montoneros se publica por primera vez en 1982 con el sello de Oxford University Press en Nueva York.

${ }^{17}$ Gillespie, Richard; Op. Cit.; p. 194.

18 Ibídem; p. 287.

${ }^{19}$ Los Montoneros poseían ya una tremenda reserva de apoyo gracias a sus iniciativas políticas relacionadas con las masas y a su sensibilidad ante la opinión pública radical. Habían suspendido su campaña guerrillera como principal fuerza de las formaciones especiales peronistas; reanudaron su actividad como la organización político militar más poderosa de la Argentina; en el curso de los doce meses siguientes se convertirín en la más potente fuerza guerrillera urbana de cuantas se han conocido en la América Latina. Gillespie, Richard; Op. Cit.; p. 203.

${ }^{20}$ Ver en Nofal, Rossana; Op. Cit.; p. 27, "Siguiendo a Hobsbawm me permito afirmar que configuran un círculo de los mitos de los pobres, de los reyes justos y de los hombres que luchan por la justicia de su pueblo. Esta es la razón por la cual estas leyendas de guerrilleros tienen aún la capacidad de emocionarnos. Son parte de esa historia que no consiste tanto en el registro documental de acontecimientos y de los personajes que los protagonizaron. Tienen la forma de un cuento de hadas que están en la base de las sagas heroicas de todas las religiones de todos los pueblos y las clases sociales.
}

${ }^{21}$ Gillespie, Richard; Op. Cit.; p. 249.

79

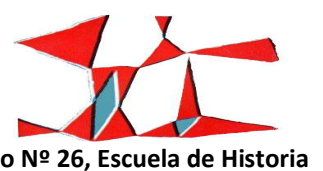

Facultad de Humanidades y Artes (Universidad Nacional de Rosario), 20164

pp. 72-89

ISSN 1853-8835 
modulaciones literarias para dar cuenta del perfil de los combatientes. Lo que se comprende tiene que ver con conjeturas imaginarias que no necesariamente pueden validarse con las referencias históricas. La representación de Tucumán en el libro expone una nueva manera de mirar las cosas: un campo de batalla. ${ }^{22}$

Andersen arriesga la hipótesis de que Mario Firmenich era informante del ejército desde $1973 .{ }^{23}$ Con la lógica del desencanto y de la denuncia, construye una narración del fracaso y desmonta los cuentos de la fuerza y las proezas de la organización insurrecta. En su capítulo “Tucumán: un rumor de guerra (1975)" presenta la provincia como un escenario de batallas falsificadas y víctimas sin agencia política. Organiza el relato de la "zona liberada" creado por la prensa "a veces de manera histérica" ${ }^{24}$ y también el escenario de la primera organización sistemática de la represión clandestina a cargo de Acdel Edgardo Vilas "general de la muerte" como le gustaba jactarse. ${ }^{25}$ Cuenta la entrada de los guerrilleros en una "aldea" en los términos de un relato sobre la "invasión de Acheral".

Veinte guerrilleros tomaron brevemente la desprotegida población de Acheral. Allí algunos de los 1800 habitantes del pueblo debieron escuchar la fogosa arenga de uno de los izquierdistas armados vestido con uniforme de fajina de color verde oliva. Entraron marchando al pueblo en formación de desfile; los insurrectos izaron una bandera azul y blanca con una estrella roja de cinco puntas, la bandera del ERP, en la plaza de la aldea. ${ }^{26}$

Andersen instala la necesidad de una investigación de los métodos de la "guerra sucia" instaurados por Vilas, manuscrito al que tiene acceso para documentar su itinerario. "Una copia del manuscrito de Vilas

\footnotetext{
22 Le tocó luego el turno a la Fuerza Aérea, que también sufrió un ataque vindicativo, esa vez por el asesinato del líder montonero Marcos Osatinsky. A últimos de agosto, un pelotón que llevaba su nombre voló por telemando la pista de aterrizaje del aeropuerto Benjamín Matienzo de San Miguel de Tucumán y destruyó un avión de transporte Hércules C-130 mientras despegaba con personal antiguerrilla. Cinco personas resultaron muertas y cuarenta heridas en aquella respuesta -la más directa de los Montoneros- a la misión militar antiguerrillera en Tucumán. Sucedió en una zona militar bien vigilada, pero la seguridad se había relajado, y la existencia de un túnel debajo de la pista -desde el cual se podía amontonar explosivos en un desagüe- fue olvidada, al parecer, por los guardianes. Nuevamente se habían invertido meses de trabajo en una operación. Los Montoneros se refirieron fríamente a ella como "una verdadera una obra de ingeniería militar". Gillespie, Richard; Op. Cit.; pp. 242 - 243.

${ }^{23}$ Martin Edwin Andersen fue corresponsal especial de Newsweek y de The Washington Post en Buenos Aires entre 1982 y 1987, y como tal cubrió los juicios a las Juntas Militares de 1985. El libro Dossier secreto. El mito de la "guerra sucia" en la Argentina, Edición actualizada y definitiva, se publica en Buenos Aires en el año 2000. La primera edición es de 1993.

${ }^{24}$ Andersen, M.; Op.Cit.; p. 160.

${ }^{25}$ Ibídem; p. 161.

${ }^{26}$ Ibídem; p. 160.
}

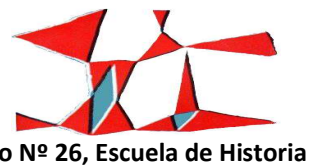

Facultad de Humanidades y Artes (Universidad Nacional de Rosario), 2014

pp. 72-89

ISSN 1853-8835 


\section{Memorias de militancia en Tucumán: los cuentos de los viejos guerreros}

que conseguí está archivada en el CELS en Buenos Aires". ${ }^{27}$ Como periodista apela a desmontar los relatos heroicos de las versiones distorsionadas de las acciones armadas.

Esta tendencia acrítica se extiende a algunos de los más notorios exponentes de las versiones distorsionadas de la historia argentina de ese período. Los Miguel Bonasso y los Horacio Verbitsky siguen vendiendo historias guerrilleras de algunos compañeros perdidos -por ejemplo, Rodolfo Walsh-con agregados de "autocríticas" que siempre parecen dejar a ellos mismos bien parados. ${ }^{28}$

En la lógica de Andersen, la guerrilla, casi compuesta en su totalidad por jóvenes, se acopló a una forma violenta de hacer política, ya "enraizada" en el país. Frente a estas, las estructuras civiles fueron extremadamente débiles para resistir. "La izquierda argentina fue siempre víctima de su propia propaganda e ilusiones". ${ }^{29}$ La aparición del libro de Daniel Gutman, Sangre en el monte. La increíble aventura del ERP en los cerros tucumanos ${ }^{30}$, expone un cambio en los marcos interpretativos de las memorias en conflicto y en los encuadramientos. Introduce la idea de aventura para instaurar una nueva lógica en la literatura de bandidos y potenciar las narrativas de lo fantástico. Los personajes se representan con iguales marcas de extrañeza en el Tucumán "rojo" que se inventa como un universo diferente de lo conocido y lo funda desde el punto inicial con las imágenes de una lógica guerrillera. Gutman construye como un real absoluto el cuento más secreto. Lo fundacional de esta ficción se resuelve mediante la lógica verosímil de la militarización de lo político y cuenta otra vez el relato ya inscripto por Andersen referido a la liberación de Acheral. El cuento se reitera con sus matrices emblemáticas: los guerrilleros desfilan con uniforme verde oliva, con fusil al hombro; son los soldados del pueblo en la calle de tierra, el día del ejército argentino. En esta polarización de lo civil y lo militar funda un discurso testimonial victorioso sobre el pasado pautado por la lógica de la guerra. El relato de Gutman replica la idea de una literatura de virtudes propuesta por Hebert Gatto; una literatura de clausura que supone la negación de elementos ambiguos o la construcción de un doble crítico que destrone a su contraparte en la idea bajtiniana del carnaval en la literatura.

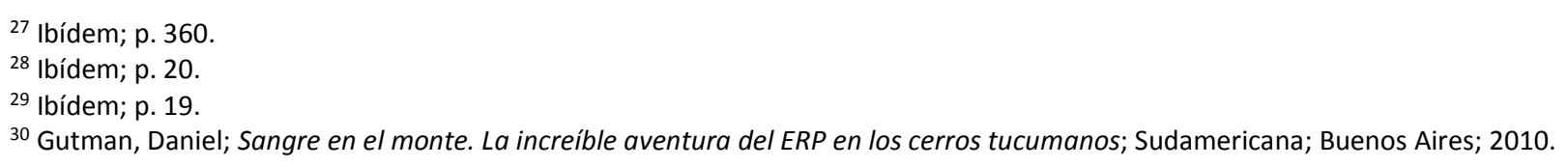

81

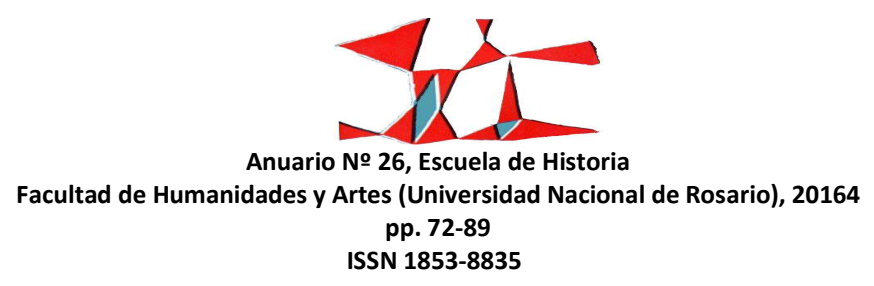


Hablamos de "una narrativa sustentada en la preponderancia de los méritos individuales de los guerrilleros -sus virtudes éticas y a veces estéticas-inhibe los análisis sobre el movimiento como organización supraindividual dotada de características propias". ${ }^{31} \mathrm{Si}$ bien han cambiado las preguntas y los personajes que construyen los testimonios, el saber sigue fuertemente ligado a un poder que lo autoriza. La extrañeza de la palabra guerra permite alejarse de las identidades narrativas de los personajes unitarios y pensar en héroes disonantes.

Entre el triunfo y la derrota viven los personajes en las tramas de las narrativas de memoria que se escriben y se publican a lo largo y a lo ancho del continente latinoamericano. Se trata de relatos que, como señala Jelin para hablar de las memorias, no respetan la linealidad del tiempo y vuelven sobre aquellos acontecimientos por esa "imposibilidad de cerrar cuentas con el pasado"32 donde quedaron los sueños de juventud y de justicia, pero también donde se anidan el desgarro del exilio, los fantasmas de la traición y la sinrazón de la tortura.

En esa zona de clivaje con una fuerte apuesta a la construcción metafórica sobre la dictadura en Tucumán, se inscribe la novela de Horacio Elsinger, La virgen de los ojos cerrados ${ }^{33}$, publicada recientemente en Buenos Aires. La novela escribe los silencios de las muertes en el interior de Tucumán. La indagación periodística sobre el asesinato de una niña lo lleva a escuchar los relatos negados sobre la represión clandestina y sus protagonistas. Enmascarado en la voz de un periodista solitario y desencantado, el autor propone la lectura de los cuentos dichos entre "viejos guerreros" ${ }^{34}$ que cuentan siempre lo mismo y los nuevos lectores que no pueden evitar escucharlos. El objetivo es historizar los relatos que no eran permeables en otras épocas: la guerra como opción política. Los juicios a los represores en los tribunales civiles abre un canal para declaraciones públicas que dicen hasta lo que no se podía enunciar; las figuraciones de los cuentos de guerra parten del presupuesto de decir lo que no se puede callar.

El relato se organiza como un inventario de historias de un tiempo anterior, los vagabundeos en el Parque 9 de Julio y los tempranos poemas de amor de un aprendiz. La novela nos propone la entrada a la vida

\footnotetext{
${ }^{31}$ Gatto, H.; Op. Cit.; p. 379.

32 Jelin, E.; Op. Cit.; p. 16.

${ }^{33}$ Elsinger, Horacio; La virgen de los ojos cerrados; De los cuatro vientos; Buenos Aires; 2014.

${ }^{34}$ Davoine, Francoise y Gaudilliere, Jean Max; Historia y trauma. La locura de las guerras; Fondo de Cultura Económica; Buenos Aires; 2011.
}

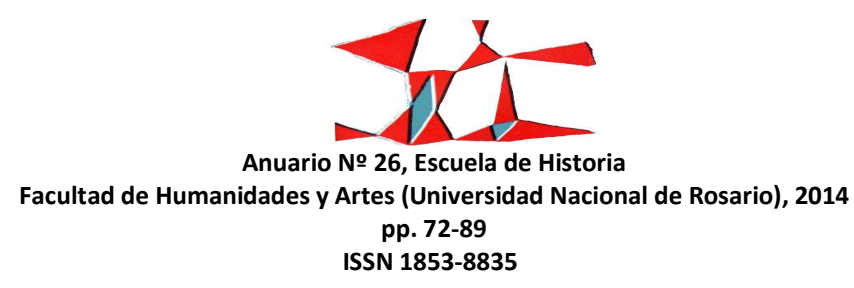




\section{Memorias de militancia en Tucumán: los cuentos de los viejos guerreros}

de Esteban Diriart. Una historia de amor que se escribe desde la derrota, la sensación de soledad, sus encuentros con su ex mujer a quien seguía pensando atractiva a pesar de los años. Inventario de hoteles y cigarrillos y la constancia de un personaje que "vive bajo el signo de lo inaugural" en el escenario de la Facultad de Filosofía y Letras, casi un histórico universal como para tantos otros intelectuales formados en la década de 1960: la bandera del espíritu crítico, la juventud, la transgresión y el pensamiento creador. Esteban se siente deudor del legado e interpelado por el mandato de escribir. ${ }^{35}$ Los periodistas no leen el diario en el que escriben.

El libro de Elsinger colecciona el listado de las rutinas escriturarias del periodismo: las letras que se miden por sus centímetros, la adrenalina de la redacción, una hora para volver a escribir el artículo, el violento oficio de escribir para el lector de noticias y para el olvido de las noticias en el desayuno.

En el no-espacio, Esteban encuentra el deseo de investigar, la inquietante muerte de la niña bella. Se escapa de los lados bajos y macabros para buscar en lo secretos de un infierno escuchado por primera vez. Hay un gesto cómplice de "experiencia compartida", una suerte de controversia entre lo público y lo privado, entre los que piensan la nota y entre los que la leen o no la leen, o sus protagonistas. Es en esa relación es en donde los individuos prefiguran sus experiencias del mundo. Esteban sale a buscar a los testigos: los padres de María Gabriela Cruz, el silencio de su madre y el oscuro y confuso pasado del padre. El contacto con el papel, el sabor del tabaco y el café. La vida que bulle a través de la ventana. Un periodista arrebatado por la vida: frente a una muerte dudosa encuentra lo que buscaba. Las respuestas esquivas e inconsistentes de los testigos interpelan a Esteban que busca certezas contundentes y razones en la muerte. Sin embargo el silencio es una palabra en el vocabulario del narrador: una palabra que se mide y se encuadra.

Frente a los relatos testimoniales y su protocolo de verosimilitud, el recurso a una forma propiamente literaria incorpora la sospecha sobre la autenticidad de la experiencia relatada, sobre la identidad del autor, del narrador y sus personajes. Estos márgenes y sus dominios borrosos permiten decir lo indecible, "introduciendo una distancia frente a los recuerdos difíciles de enfrentar con las normas de la moral corriente" ${ }^{36}$ En el pasaje a la ficción, la persona se convierte en personaje y se evita la referencia a hechos

\footnotetext{
${ }^{35}$ Elsinger, H.; Op. Cit.; p. 79.

${ }^{36}$ Pollak, Michael; Memoria, olvido, silencio. La producción social de identidades frente a situaciones límite; Al margen; La Plata; 2006; p. 88.
}

83

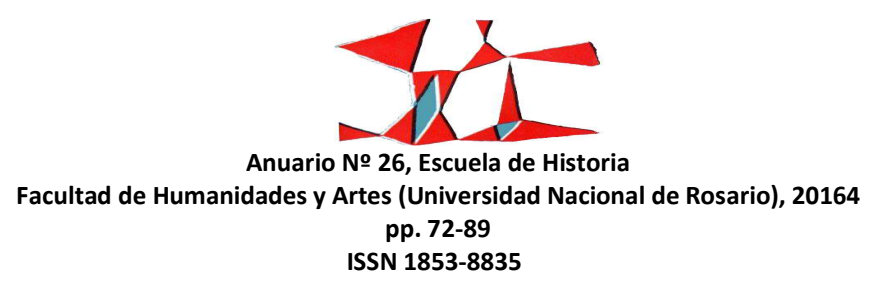


reales, siempre sujetos a una contestación. Como explorador memorioso, Esteban Diriart se encuentra con la "guerra sucia" en la parte de las "revelaciones" del Libro de Gabriel. Un libro fotocopiado que ilumina la fiesta del monstruo y sus móviles: cómo pensaban los enemigos. El relato testimonia los modos de apropiación local de las tácticas de la guerrilla. Un libro que explicita la dinámica de la guerra sucia desde sus actores. Actualiza el relato maestro del manuscrito de Vilas buscado por Andersen y relatado por sus ocasionales lectores en la provincia. El manuscrito expone lo indecible de un manual del torturador.

De él aprendimos los beneficios de la clandestinidad y la importancia del factor sorpresa. Había que salirse de las reglas de la guerra clásica.

Nosotros fuimos más allá y nos salimos de toda regla, de toda ley. Vencimos porque logramos superar largamente nuestro enemigo en astucia y crueldad. No tuvimos reparos morales ni consideraciones de ningún tipo. Nada nos detuvo. Vencimos porque no nos pusimos ningún límite ni renunciamos a nada en nuestro propósito de aniquilar al enemigo. (...) Fue sobre el final de la guerra, cuando el enemigo estaba prácticamente derrotado, que tuvo lugar una experiencia que provocaría un giro decisivo en mi vida. El momento de la verdad llegó una noche en que interrogábamos a un prisionero para acabar con sus últimos reductos". ${ }^{37}$

Cruz era el encargado de torturar, prometer lo peor y amenazar con la aparición del Coronel. ¿Quién es el Coronel? Todo en este discurso está cifrado. La rugosidad y la complejidad de la guerra se exponen en el viaje primero al interior y luego a la localidad de Cachi en Salta. Esteban emprende este viaje a la semilla del infierno desde su ciudad. Un desajuste cronológico organiza la entrada del narrador a un mundo otro con una foto robada del Coronel, en el que aparece con nombre figurado y en la que los ojos parecen mirarlo desde la imagen y lo desconciertan. La incertidumbre de esta mirada contrasta con los ojos vendados de la niña muerta sin mirada, sin identidad. Sobre el final de la novela se abre su metáfora más desafiante: la luz que resalta en un ambiente oscuro y anuncia lo siniestro de la muerte. La Anunciación a María como clave alegórica para explicar el infierno y sus letanías de entrada.

En una de las paredes colgaba una pintura que le llamó la atención. Esteban se incorporó de su asiento para observar el cuadro desde más cerca. Un ángel de bucles dorados parado frente a una María muy joven señalaba el vientre de ésta con su índice. Una luz suave iluminaba la escena. Es una Anunciación de autor anónimo -dijo la voz a sus espaldas y agregó-. Pertenece a mi familia desde hace muchos años. ${ }^{38}$

\footnotetext{
${ }^{37}$ Elsinger, H.; Op. Cit.; p. 144.
}

38 Ibídem; p. 160.

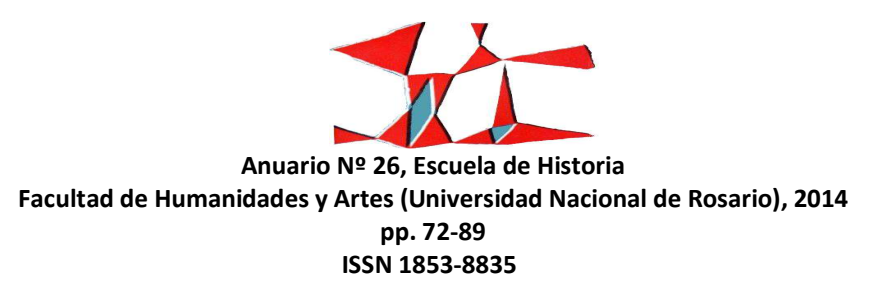




\section{Memorias de militancia en Tucumán: los cuentos de los viejos guerreros}

María llena eres de gracia. ¿Quién mató a la niña? La metáfora de la anunciación re describe la realidad. No engendra un nuevo orden sino que produce desviaciones en el orden anterior. La secta reproduce la escala del genocidio de la dictadura. La foto con la imagen de una víctima inmolada inscribe la metáfora que altera la lógica mimética del realismo periodístico mediante una atribución aberrante del vacío. Elsinger reconfigura los modos de pensar el pasado al percibir la semejanza entre el pasado y las configuraciones siniestras de una secta presente. Desplaza las temporalidades y en una ampliación del sentido de las palabras arrebata los cuerpos de las víctimas del olvido de los pueblos. Sobre el final inscribe la voluntad de clausura: "Y si fuese el fin del mundo que llegaba una tarde cualquiera (...) No había otro cielo ni otro infierno". ${ }^{39}$ El infierno es, en realidad, la verdad del horror del pasado revisitado por una investigación en un presente igualmente silenciado.

\section{Coda}

En un artículo del año $2004^{40}$, Elizabeth Jelin analiza el surgimiento de un nuevo campo de preocupaciones en las ciencias sociales latinoamericanas: los derechos humanos y las memorias de la represión y la violencia política. En este desarrollo narra los antecedentes conceptuales y las condiciones históricas que dieron lugar al surgimiento de este campo interdisciplinario en el que se inscriben las marcas propias de su biografía intelectual. Con un rol protagónico en los hacedores del campo, Jelin siempre habló sobre la necesidad de redefinir las fronteras entre los espacios públicos y los privados a la luz de la dimensión de la vida cotidiana representada en las relaciones sociales que se desarrollan en el día a día. Las tensiones entre la urgencia de rememorar y recordar los hechos, los huecos traumáticos y las heridas abiertas constituyen el principal tema de investigación del campo, pero también su obstáculo más grande: la paradoja de decir lo indecible. ${ }^{41}$

\footnotetext{
39 Ibídem; p. 209.

40 Jelin, Elizabeth; "Los derechos humanos y la memoria de la violencia política y la represión: La construcción de un campo nuevo en las ciencias sociales"; Estudios Sociales, Revista Universitaria Semestral; Año XIV; № 27; Universidad Nacional del Litoral; Santa Fe; 2004; pp. 91-113.

${ }^{41}$ Jelin, Elizabeth; Los trabajos de la memoria; Op. Cit.
}

85

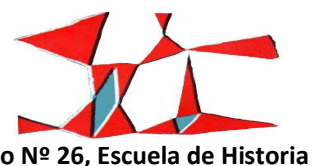

Facultad de Humanidades y Artes (Universidad Nacional de Rosario), 20164

pp. 72-89

ISSN 1853-8835 
Igualmente Jelin pensó, como un mandato epistemológico, la necesidad "de que la investigación siempre historice las memorias". ${ }^{42}$ Sumó a sus presupuestos la compleja definición de las temporalidades de Koselleck, entendidas como la vinculación del tiempo histórico con las experiencias de los hombres que viven y actúan en ese escenario. Las experiencias nunca se inscriben como discursos lineales. Esta es una de las profundas advertencias de Jelin: escuchar los matices de cada relato. Las experiencias y las temporalidades se superponen, se entremezclan y se articulan siempre desde el conflicto.

La lectura de las múltiples temporalidades implica ubicar coyunturas que activan memorias subterráneas, habilitan nuevas interpretaciones de las mismas escrituras e iluminan los silencios deliberados en los textos leídos una y mil veces. Implica también pensar las regiones con sus distintas vías, sus tiempos y sus verdades. En este sentido, el desarrollo del concepto de "cuentos de guerra" entendidos como partículas narrativas inscriptas en múltiples relatos ${ }^{43}$ ubica a la escritura de Elsinger y a su autor no sólo en el espacio de experiencia sino también en el "horizonte de expectativa" que hace referencia a una temporalidad futura para su propia obra, "nuevas esperanzas o desengaños, nuevas expectativas, abren brechas y repercuten en ellas". ${ }^{44}$ Releer el género a contrapelo del mandato político e iluminando las construcciones metafóricas permite la emergencia de las voces grises, los lados más bajos: el lugar de los otros monstruosos de esta historia que se inscribe en el relato de la anciana, hermana de Sorel "el mismísimo Coronel".

\begin{abstract}
Después de una temporada en el infierno, recuerdo que decía, sólo quiero encontrar un poco de sosiego para mi alma. Mi padre falleció al año siguiente, creo que nunca pudo reponerse de la frustración de ver la carrera militar de su hijo truncada. De todos modos la muerte lo libró de una amargura mayor. Dos años después de su fallecimiento, con la normalización constitucional del país, comenzaron los juicios contra los militares. Mi hermano, junto a otros camaradas suyos, fue acusado de haber cometido torturas y asesinatos. La gente que había luchado para que el país no terminase bajo una dictadura atea, ahora era perseguida y presentada como el mismísimo demonio. ¿Usted puede entenderlo? (...) Esteban que seguía atento el relato de la mujer, no supo qué decir. Lo peor que podía sucederle pensó era enfrascarse en una discusión política con la entrevistada. ${ }^{45}$
\end{abstract}

\footnotetext{
42 Jelin, Elizabeth; "Los derechos humanos..."; p. 103.

${ }^{43}$ Inicialmente tomo el concepto de Josefina Ludmer; Op. Cit; p. 148, que define cuento en términos de matrices productoras que pueden ser diversas e indefinidas; "están entrelazadas y forman nudos; quizás los únicos rasgos

${ }^{44}$ Koselleck, Reinhart; Futuro pasado. Para una semántica de los tiempos históricos; Paidós; Barcelona; 1993; p. 341.

${ }^{45}$ Elsinger, H.; Op. Cit.; p. 162.
}

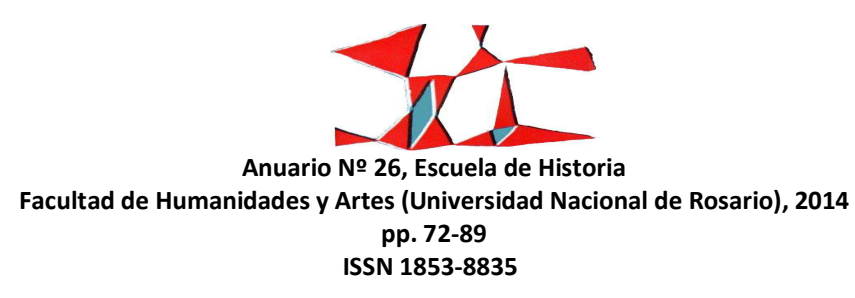




\section{Memorias de militancia en Tucumán: los cuentos de los viejos guerreros}

Memorias contra memorias en términos de Jelin. "El escenario de las luchas políticas por la memoria no es simplemente una confrontación entre memoria y olvido, sino entre distintas memorias". ${ }^{46} \mathrm{Ante}$ un tribunal, señala Paul Ricoeur, "la plurivocidad común a los textos y a las acciones se exhibe en la forma de un conflicto de interpretaciones y la interpretación final aparece como un veredicto ante el cual es posible apelar" $^{\prime 47}$. Pero en el tribunal llega un momento en el que los procedimientos de apelación se agotan y se impone la decisión del juez. El testimonio se ocupó de estas instancias: juzgar, de construir pruebas, acusar y condenar.

Esteban Didart oficia de querellante en juicios inexistentes. A partir de la instauración de los Juicios por la verdad, el género comenzó a separarse de sus mandatos iniciales y aligeró su "responsabilidad" como última palabra entre la inocencia y la culpabilidad pero continuó asumiendo su protocolo en la construcción de pruebas de verdad y su vinculación con el periodismo. Todo está cifrado en la escritura de Elsinger. El concepto de "trabajos de la memoria" de Jelin pensado como un relato posible sobre la violencia política supone enfatizar lo activo de las personas y de las sociedades, poner el acento en los agentes que elaboran los sentidos simbólicos del pasado y en las disputas que esos agentes tienen dentro de la esfera pública. Estamos hablando entonces de desmontar los postulados heroicos. La posibilidad de leer la idea de guerra como un cuento que permanece inmutable en los relatos, permite pensar en encadenamientos de las historias sin sucesiones; los cuentos pueden modificar las cronologías hasta el punto de suprimirlas. Es necesario, entonces, un modelo móvil, con la suficiente plasticidad para moverse en el espesor del sistema; un aparato de lectura para explicar el espesor, para volver audibles los conflictos, las tensiones, los ocultamientos, los juegos y sus urdimbres.

La retórica de la metáfora permite que la guerra, como unidad de referencia de los textos anteriores sobre Tucumán, exponga su lado más oscuro y siniestro en la novela de Elsinger. La palabra guerra abandona el romanticismo militante de los primeros relatos testimoniales sobre Tucumán y amplía sus sentidos hacia la lógica del exterminio. La novela tiende a alterar todo el sistema de representación testimonial mediante una atribución aberrante: quien mató a la niña es su propio padre, aprendiz del torturador que anuncia al Coronel. Reescribe la cronología en los términos de los silencios de un pueblo y de los secretos de la represión. La

${ }^{46}$ Jelin, Elizabeth; "Los derechos humanos..."; Op. Cit.

${ }^{47}$ Ricoeur, Paul; Del texto a la acción; Fondo de Cultura Económica; Buenos Aires; 2006; p. 188.

87

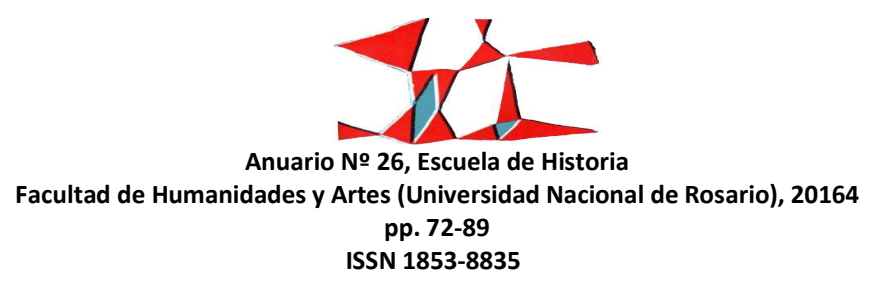


metáfora de Elsinger no engendra un nuevo orden sino que explicita los silencios de las memorias subterráneas que todavía es sanción de todo lo que el narrador puede referir. De ella tiene prestada su autoridad", señala Benjamin. ${ }^{48}$ La muerte referida y el viaje del narrador son las dos figuras con las que Elsinger reinstala la figura en el tapiz y cuenta, desde el lado de acá, los secretos sin escucha en el lado de allá.

\section{Bibliografía}

Jelin, Elizabeth y Kaufman, Susana (comps.); Subjetividad y figuras de la memoria; Siglo XXI; Buenos Aires; 2006; p. 68

Alcoba, Laura; La casa de los conejos; Edhasa; Buenos Aires; 2007; p. 84.

Gillespie, Richard; Soldados de Perón. Los Montoneros; Grijalbo; Buenos Aires; 1986.

Andersen, Martin Edwin; Dossier secreto. El mito de la "guerra sucia" en Argentina; Sudamericana; Buenos Aires; 2000.

Anguita, Eduardo; La compañía de monte; Planeta; Buenos Aires; 2005

Mercado, Lucía; Santa Lucía de Tucumán. La Base; Ediciones del Autor; Buenos Aires; 2005.

Rama, Ángel; La ciudad letrada; Fundación Ángel Rama; Montevideo; 1985.

Ludmer, Josefina; Los procesos de construcción del relato; Sudamericana; Buenos Aires; 1977.

Gatto, Herbet; El cielo por asalto. El Movimiento de Liberación Nacional (Tupamaros) y la izquierda uruguaya (1963-1972); Taurus; Montevideo; 2004; p. 379.

Jelin, Elizabeth; Los trabajos de la memoria; Siglo XXI; Buenos Aires; 2002.

Nofal, Rossana; "Desaparecidos, militantes y soldados"; en Crenzel, Emilio (comp.); Los desaparecidos en Argentina; Biblos; Buenos Aires; 2010.

Schmucler, Héctor (comp.); Miedos y memorias en las sociedades contemporáneas; Comunic-arte; Córdoba; 2006.

Gutman, Daniel; Sangre en el monte. La increíble aventura del ERP en los cerros tucumanos; Sudamericana; Buenos Aires; 2010.

${ }^{48}$ Benjamin, Walter; El narrador; Metales pesados; Santiago de Chile; 2008; p. 75.

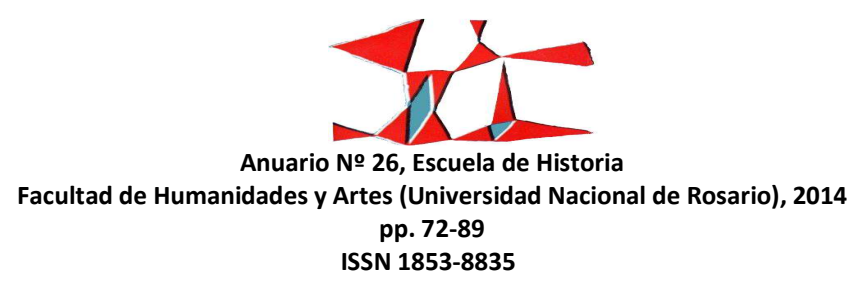




\section{Memorias de militancia en Tucumán: los cuentos de los viejos guerreros}

Elsinger, Horacio; La virgen de los ojos cerrados; De los cuatro vientos; Buenos Aires; 2014.

Davoine, Francoise y Gaudilliere, Jean Max; Historia y trauma. La locura de las guerras; Fondo de Cultura Económica; Buenos Aires; 2011.

Pollak, Michael; Memoria, olvido, silencio. La producción social de identidades frente a situaciones límite; Al margen; La Plata; 2006.

Jelin, Elizabeth; "Los derechos humanos y la memoria de la violencia política y la represión: La construcción de un campo nuevo en las ciencias sociales"; Estudios Sociales, Revista Universitaria Semestral; Año XIV; № 27; Universidad Nacional del Litoral; Santa Fe; 2004.

Koselleck, Reinhart; Futuro pasado. Para una semántica de los tiempos históricos; Paidós; Barcelona; 1993

Ricoeur, Paul; Del texto a la acción; Fondo de Cultura Económica; Buenos Aires; 2006

Benjamin, Walter; El narrador; Metales pesados; Santiago de Chile; 2008

Recibido: 5 de agosto de 2014

Aprobado: 15 de octubre de 2014

Versión Final: 4 de diciembre de 2014

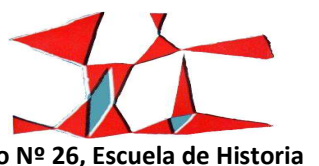

Facultad de Humanidades y Artes (Universidad Nacional de Rosario), 20164

pp. $72-89$

ISSN 1853-8835 